\title{
Relationship between Business Competency and Employee Performance Improvement: A Study of Nepalese Banking Sector
}

\author{
Dhruba Raj Pokharel, Ph.D. \\ Associate Professor, Nepal Commerce Campus, T.U. \\ Sumedha Sharma \\ Padma Kanya M. Campus \\ Bimika Dhakal \\ Nepal Commerce Campus
}

\begin{abstract}
This study describes the employees' business competency and performance improvement and their relationship on the basis of responses collected from selected commercial banks inside Kathmandu valley. The main objective of this study was to analyze the employees' perception on business competency and performance improvement in the banking industry of Nepal.

This study adopted a descriptive and comparative design. The size for the research were 210 respondents. Primary data were collected from employee working in banks through a set of a structured questionnaire for the research. To analyze the collected data, mean, standard deviations and Pearson correlation analysis were conducted to identify the relationship between independent variables (Business competency) and dependent variable (Employee performance improvement. This research conformed that Nepalese employees in banking sector are aware of business competency and performance improvement. There is a strong correlation between employees' business competency and performance improvement.
\end{abstract}

Keywords: Business Competency, Performance improvement, Nepalese commercial Banks, Employees'competency

\section{Background of the Study}

Competency has its origins in the Latin word "competentia' which means "is authorized to judge" as well as "the right to speak" (Caupin, Gills; International Project Management Association, 2006). The concept of "competency" was first brought in academic discourse by Selznick, (1957), White (1959), and subsequently McClelland (1973) remarkably developed the concept of "competency" as significant predictors of employee performance and success. Competencies emerged in the 1980s as a response to organizational changes and wider changes in society (Chartered Institute of Personnel and Development, 2007) Competency means 'the underlying attributes' of an individual, such as knowledge, skills, or abilities. It is well described as the capability or ability of a person which makes it possible for them to deliver superior performance in each role, job, or situation. Competency is defined as 'an underlying characteristic of a person which results in effective and/ or superior performancein a job'. In the views of Boyatzis (1982) the underlying characteristic of a competent person should include a motive, trait, skill, an aspect of one's self-image or social role, or a body of knowledge.

To meet global competition, business organizations must be driven by human skills and expertise. 
Organizations depend on their employees as a main resource and management needs should be oriented towards the strategic utilization of human resources (HR). Unlike other resources, HR is the only asset that can appreciate with user inputs. It is one such asset that adds value to itself with time and, therefore, it is considered as a resource that can be cultivated by the manure of training and development processes (Kansal, Satyawali, Jain, \& Ganju, 2012). Due to this, many approaches and techniques have been developed for ensuring that human resources are managed and developed in such a way such that it aligns with the goals and strategies of the organization.

Today the businesses are epitomized by global operations, workforce diversity, transitions, paradigm shifts, competition, wealth creation, shareholder value maximization, customer focus, culture, and valuebased product, and context-based approach. The organizational success in the past depended on physical and financial assets, today the success relies on the intangible ability and capability that rests in the human resources and manifested in the form of competencies. Competency of HR is an intangible resource that can take a company forward. Employee competency acts as a catalyst to stay competitive and achieve the sustainable competitive advantage of the firm in the face of various difficulties that day in and day out squeezes and tatters its existence, unless the competency is acquired, developed, and preserved. The root of the organizational existence and growth in this knowledge age is centered upon employee competency which lies as seed unless explored, nourished and nurtured, to achieve competitive advantage for the firm. Given the fact that environments are becoming progressively more dynamic, strategic planning derived from static and rational view have lost their relevance and failed to be adequate. To build a competitive advantage in a varying environment, firms are now focusing on building core competence. An essential factor associated with an organization's long-run success is the ability to measure how well employees perform and to apply that information to obtain the prolific results. In a knowledge-based economy, organizations need to assess workforce competency and develop them regularly (Srivastava, 2014). Competencies can provide an organization with the value addition. Competencies of employees drive the organization on the path of development and give the organization a distinct competitive advantage, which an organization looks to attain through the strategic deployment of extremely dedicated and competent employees utilizing a collection of cultural, structural, and personnel techniques.

As global business competition shifts from efficiency to innovation and from enlargement of scale to the creation of value, management needs are oriented towards the strategic use of human resources (Gluck, 1980). These changes necessitate innovative approaches in managing human resources. One of the most used HR practice nowadays is competency mapping. Competency mapping serves the organizations as an important and innovative management tool designed to give a competitive advantage in terms of people process organizations. Identifying, nurturing, and utilizing the employee competencies in the organization enables better performance management as well as reward and recognition systems leading to career and succession planning programs.

There is a strong business case for competencies at work as they lead to significant human resource development that provides organizations with a competitive edge (Vazirani, 2010). The biggest challenge of any business is to sustain and grow. To compete it is essential to know what competencies a business need. Strategies can only be effectively implemented if organizations have a competent force of employees. The dynamic and growing organizations require a continuous review of its structure and systems, creating new roles and responsibilities for their employees. Matching the competency of an individual with these new roles and responsibilities will enable organizations to develop the skill set that will ultimately help to drive the business strategy and achieve business goals. Many organizations have found that the competency of their workforce is key to gain a competitive advantage. Nowadays organizations are more concerned about their human competency base and its development (Ferman and Ozcelik, 2006); consequently, competency studies have gained more and more interest and attention (Qiao \& Wang, 2009).

Dynamic trends in the external business environment, in the challenges that companies face, and in the nature of HR itself demand that HR departments develop new capabilities and that HR professionals 
develop new competencies (Quinn \& Brockbank, 2006). The business dynamics to which the HR field must respond and contribute are increasingly turbulent (Ulrich \& Brockbank, 2005). There is an incredible number of pressures on business organizations these days. To name a few: environmental pressures such as increasing globalization, rapid technological change, and tougher competition; organizational changes such as new organizational alliances, new structures \& hierarchies, new ways of assigning work, and a very high rate of change; changes in the workforce, including employees' priorities, capabilities, and demographic characteristics. Within these organizations, there is a need for (or opportunity for) the human resource function to play a critical role in helping organizations navigates through these transitions. To play this role, however, HR will have to increase its real and perceived value. Today, many pressures are deeming a broader, more comprehensive and more strategic perspective about the organization's human resources. These pressures have created a need for a long-term perspective in managing people and consideration of people as potential assets rather than merely a variable cost (Lapina, Maurane, \& Starineca, 2013).

Fundamentally competency models/frameworks contain numerous competencies that are considered vital for a particular job/occupation or a task. Each competency is mapped with its equivalent capability levels/required competence level. Individuals can be profiled in opposition to the capability (mastery) level / required competence level and the attainment level of the competency can be identified. Both positive and/ or negative gaps of the individuals can be determined. A competency framework is particularly helpful in measuring the attainment of the competency of an individual.

\section{The Problem Statement}

In the world of management professionals, the term competency has gained more importance today. Organizations are vying globally, and they wanted to create a competitive edge over the other. Nepalese commercial banks are investing a tremendous amount of time and money to have competent employees or they develop ordinary employees into extra-ordinary employees by developing distinguishable competencies. Managers and HR professionals have realized the importance of competency mapping and they believe that the future belongs to competent people and competency-based banks.

A review of literature on the subjects relating to the framework which includes competencies, individual competency framework, training needs, and performance was done. This review of extensive literature brought about a clear understanding of theories and concepts, which are pertinent to the carry out the research in this field, as proved by other researchers.

The followings have been observed as the research gap based on the review of literature:

The prominent role of competency development in enhancing the success of employees and organizations has drawn the attention of practitioners leading them to introduce competency development as a central part of their HR practices (Delamare Le Deist \& Winterton, (2005). As a result, the use of competencies within HRM has become widespread in today's organizations (Athey \& Orth, 1999; Heinsman, De Hoogh, Vanmuijen, \& Koopman, 2006; Nybo, 2004). Unfortunately, scholars have often been skeptical towards the concept of competencies and thus the strong managerial interest in competency development was not fully translated into the academic world, leading to a gap between theory and practice. Athey and Orth, 1999; Barret \& Depinet, 1991; Hsu \& Leat, 2000 observe that in the academic literature, many of the prominent theoretical or analytical models of HRM and strategic HRM have been developed by USA or European researchers. Most of these models reflect the cultural characteristics of their country of origin and this sometimes raises questions about the applicability of those western-oriented models in a different cultural and contextual environment. Hsu and Leat, (2000); Boxall and Dowling, (1990); Khatri, (1999); Nankervis, Compton, and McCarthy, (1999); Budhwar and Debrah, (2001) assert that HR competency models/frameworks developed in the west may not be suitable in the other parts of the world due to the different culture and diversity.

There has been a large degree of research concerning HR competency models in the western context. Not much work has been done in Asia. There appears to be a paucity of research in the development of 
empirically tested local indigenous HR frameworks in the Asian context and more research needs to be carried out (Chen, Bian, \& Hom, 2005; Khatri, 1999; Abdullah, Musa, \& Ali , 2011). Very few empirical frameworks have been developed in Asia, and particularly in India. Conducting studies in different parts of the world, especially in India would help to meet the shortage of empirical work in the field in those parts of the world and serve as a vehicle for comparative studies.

Finally, the number of HR competency studies relating to competencies and performance is extremely small. Further research on the link between competencies and performance is crucial (Chen, Bian, \& Hom, 2005; Abdullah, Musa, \& Ali , 2011). To fill these gaps, the proposed research study is taken up which aims to establish and develop HR competency model by conducting a study.

To sum above the present research attempts to address the issue of business competencies and their relationship with performance improvement of the employees working in the selected commercial banks in Nepal.

\section{Propose of the Study}

The basic propose of the study is to analyze the influence of business competency on employee performance improvement in the banking sector of Nepal. It also wants to show the relationship of business competency with the in the improvement in performance of the employees working in the selected banks.

\section{The Research Methods}

The present research is based on the descriptive and analytical research design. Primary data for the study were collected in the month of January, 2020. A standard questionnaire was used to collect the data. The questionnaire used in this work was based on the work of Sharma (2013). Necessary changes were made to suit with Nepalese managerial context. The opinions of practicing managers and the experts in subject matter have been given due respect while finalizing the survey instrument. The questionnaire was constructed in the unipolar scale. The respondents were requested to give their perceptual opinion as strongly agree (1) and least agree (5) to each statement. Before final survey a pilot test of survey instrument was performed with 40 respondents to test the validity and accuracy.

Out of 27 commercial banks operating in Nepalese economy 12 banks were selected as a sample of the study. Non-probability convenience sampling method was used to sample banks and their employees as respondents. Total 300 employees from the 12 banks were selected as the sample of respondents. Out of 300 questions distributed, 210 valid and usable responses were collected. Thus the valid response rate of this study was 70 percent. The gender classification of the respondents comprises $113(54 \%)$ male and 97 (46\%) female. Among the 210 responses received 85 (42\%), $74(35 \%), 26(12 \%)$ and $24(11 \%)$ were from the age group of 20 to 25 years, 26 to 30 years, 31 to 35 years and above 35 years respectively.

The collected data from structured close ended questionnaire was duly entered into MS Excel and SPSS version 23 for window. Descriptive statistics like mean and standard deviation were calculated to find the average perception of respondents on the given statements. The correlation analysis was conducted to find the relationship between business competency as independent variable and employees' performance improvement as dependent variable.

\section{Scope and Limitations of the Study}

There have been many empirical investigations, analyses, and studies about how business competency can contribute to employee performance improvement. This research paper mainly examines the relationship between business competency and employee performance improvement in the selected commercial banks in Nepal. The study is constrained by time and resource limitations. The research was mainly conducted considering, only a few variables of business competency and employees' performance improvement. However, there could be other groups which would have impacted the employee performance improvement, which was not considered. Similarly, this study was conducted using a sample from twelve 
different commercial banks which cannot be generalized across other commercial banks. Thus the research in hands has been particularly prepared with the help of perceptual information or data obtained from a limited number of employees. The statistical tools applied to reach the findings are simple. However, an attempt has been made to make it as authentic and realistic as possible.

\section{Literature Review}

A 'Competency' may be referred to as behavior or set of behaviors which is the outcome of knowledge, skill, and attitude including traits, motives, values, and beliefs that enables superior performance in a particular work context. Further, Avkiran (2000) has described 'Competence' as those areas of a manager's work where he or she is capable of performing the task effectively. In brief, it can be understood as an observable behavior that demonstrates skills, learnings, and experiences.

\section{Review of Literature Relating to Business Competency}

From the company's viewpoint, competency is a multi-functional integration and harmonization of capabilities. For a corporation involved in diversified businesses, competencies are a cluster of know-hows and skills owned by a strategic business unit (Javidan, 1998). While core competencies are situated at the highest level in a competencies hierarchy and are a result of the interaction between all strategic business units' competencies. Javidan (1998) identified four core competencies for a natural gas pipeline company: (1) operate safe, sound, cost-effective facilities, (2) manage regulatory processes, (3) develop and manage projects, and (4) avoid risk. From the individual employee's viewpoint, competency is defined as a personrelated concept referring to a cluster of dimensions of behavior that enable one to perform well at work (Selmer \& Chiu, 2004).

There are many discussions on organizational competence that should ensure successful competition in the market. Some authors analyze the evolution of competence theory (Escrig-Tena \& Bou-Llusar, 2005; Hong \& Ståhle, 2005), others - competence typologies and approaches (Baker, Mapes, New, and Szwejczewsk, 1997; Drejer, 2001; Lado, Boyd, \& Wright, 1992; Leonard-Barton, 1995), and the others -competence building, leveraging and maintenance (Sanchez \& Heene, 1997). This paper is in line with the idea that separate isolated organizational competences in today's market are provided with minimum possibilities to ensure a competitive advantage for the organization (Dulewitz, 1991).

Becker and Huselid (1998), business-related competencies refer to the business skills and experiences that employees possess outside their functional specialism. Business competencies also have a strong influence on corporate financial performance. Rothwell, Sanders, and Soper (1999) defined business competencies as "those that are associated with the understanding of organizations as systems and of the process, decision-making criteria, and issues that businesses face". McDaniel (1998) conceived business competency as "a competency that applies to many different positions in a company". Unfortunately, common problems nowadays are that HR professionals do not possess adequate working knowledge of what business is all about, or of the strategic goals of the organizations. To become key players in an organization, HR professionals must understand the business or industry of the company they serve. The labor factor, representing institutional constraints such as labor legislation, is the third factor that constitutes the domain of business knowledge (Boselie \& Paauwe, 2005). HR professionals must understand how their business or agency operates. Therefore, HR professionals should develop their knowledge of such areas as finance, marketing, operations, and general management. Expertise in these areas helps HR professionals create value by enabling them to link their actions more effectively to the organization's strategy (Heisler, 2003). As one of the main barriers for the ability of HR professionals to play a more strategic role in an organization is their lack of competencies (Aitchison, 2007); the impact of business competencies on performance must be assessed.

Ramlall(2006) carried out a study on HR competencies and found that the most important competencies for the HR professionals were knowledge of business, HR delivery, and strategic contribution. However, in 
the study, the HR professionals, too, ranked their competency levels and the highest-ranked competencies were: the ability to deliver HR services, technical competencies in HR, ability to manage change, selfassessment of knowledge of the business, and the ability to manage an organization's culture.

In Malaysia, Junaidah (2007) carried out an empirical study on the type and level of competencies possessed by the HR managers from the top management perspective. The competency domains studied include business mastery, human resource mastery, change mastery, organizational culture mastery, and personal credibility. The sample of the study consists of medium-sized Malaysian manufacturing companies with not more than 1000 employees. Based on the study, the HR managers are satisfactorily competent in business mastery, they are competent in human resource management mastery, unsatisfactorily competent in managing change mastery, fairy competent in managing culture mastery, and satisfactorily competent in personal credibility.

Selmer and Randy (2004) surveyed 3000 HR professionals, consultants, line executives, and academicians in Hong Kong. The empirical study carried out outlines that HR professionals should master both traditional and new skill areas including HRM concepts and functional knowledge, communication, project management, international management, diversity management, market knowledge, international leadership, continuous change and innovation, strategic problem solving, community relations, business partnerships, employee involvement, employee champion, team development, empowerment, organization development, and global business knowledge. Ramlall (2006) carried out a study on HR competencies and it was found that the most important competencies for the HR professionals were knowledge of business, HR delivery, and strategic contribution. However, in the study, the HR professionals, too, ranked their competency levels and the highest-ranked competencies were: the ability to deliver HR services, technical competencies in HR, ability to manage change, self-assessment of knowledge of the business, and the ability to manage an organization's culture.

Selmer and Randy (2004) assert that in the study conducted by the Hong Kong Institute of Human Resource Management and the University of Michigan's Business School in 1998, the competency “change agent" was the biggest challenge faced by the HR professionals. The study, too, observes that, as HRM responsibilities change from a function-oriented to a process-oriented culture; HR managers need to initiate and coordinate business processes or subsystems to offer services that contribute to organizational and business successes.

The research on managerial competencies gained momentum since Boyatzis,(1982) identified the competencies specific to managerial effectiveness. Schoonover (2003) argues that environmental changes transform the way organizations create value and conduct businesses. Besides new capabilities, specific functional direction, and a set of roles, HR practitioners must also master competencies to meet the challenges. Although the three basic roles of HR specialists, HR generalists, and HR strategists still predominate, the responsibilities of each have expanded significantly. Schoonover suggests that a competency framework must be structured into four building blocks. These include personal attributes, leadership and management competencies, HR core competencies, and HR role-specific competencies (Schoonover, 2003).

\section{Review of Related Literature on Employees' Performance Improvement}

Over the years, organizations and industry have utilized diverse approaches to performance management of employees. With a dire need for transformation to match environmental dynamics, the trend to use competency-based approaches for assessment, and development of workers has experienced a significant emergence. Organizations have turned their focus from skills acquisition and assessment to the competency modeling process for determining the needs of business and employers. Competency-based human resource management (CBHRM) utilizes the concept of competency analysis to inform and improve the processes of recruitment and selection as well as performance management (Armstrong, 2005).

Competencies represent the language of performance. Two of the assumptions of competency-based human resource management (CBHRM) are that practitioners can identify the knowledge, skills, abilities, 
and other attributes (KSAO's) required in a given organizational role and subsequently, measure or assess the degree to which these KSAO's are possessed by individuals. As organizations evolve and create new strategic plans to meet ever-changing business challenges, they must also define their ideal talent profile. Talent profiles ought to be future-focused, answering such questions as, "What will people need to do to be able to achieve business goals?" "What kind of leadership is needed to achieve the targeted growth and profitability?" Talent profiles are based on competencies hence interviews and the selection process must be aligned accordingly. Competency model aligns talent with business goals or the strategic focus of an organization. In a sense, an individual's technical, as well as their characteristics and attributes must be a fit with the corporate culture to be hired by an organization and be successful on the job. Without these attributes or competencies, the individual is not considered qualified (King, King, \& Rothel, 2001). In other words, the possession of these traits is assumed to lead to expected or desired performance. Assessing and evaluating the performance of an individual through a competency-based performance appraisal system and providing guided training and professional development opportunities based on the competency model must also be included in an agency's practices. A successful organization will consider the competency model when selecting and hiring new employees but will also be using the competency model to develop and advance incumbent employees. In some companies, successful succession planning requires updating competency models or job descriptions, recognizing internal talent through assessment, and developing such talent through training (Egodigwe, 2006).

\section{Data Analysis and Presentation}

The following sections of the paper is devoted to present the perceptual views of the employees' working in the selected commercial banks in Nepal.

\section{Business Competency}

Seven questions were asked regarding business competency. Table No. 1 shows the mean and standard deviation of the business competency of respondents. The respondents were requested to indicate their opinion in the scale like strongly agree (1), agree (2), agree somewhat (3), less agree (4) or least agree (5). A mean less than 3 indicates that the average agreement of the respondents is high. Whereas mean higher than 3 represents that the respondents' agreement to the statements is low. Similarly, the mean equal to 3 indicates that the respondents are agreeing somewhat to the statement. Table 1 presents the descriptive analysis.

As presented in table 1, for the first statement "I am required to sit whole day in office", the mean value computed was lowest i.e. 1.03 which means that respondents are strongly agreeing to the statement. In case of the statement, "I could not become successful in this job without detailed knowledge of the business domains" the computed mean value was 2.74 which means that respondents are somewhat agreeing to the statement.

\section{Table 1}

Descriptive analysis of business competency

\begin{tabular}{llll}
\hline Statements & $\mathrm{N}$ & Mean & Std. Deviation \\
\hline I am required to sit the whole day in the office. & 2100 & 1.03 & 0.1669 \\
$\begin{array}{l}\text { I could not become successful in this job without detailed knowledge of } \\
\text { the business domains. }\end{array}$ & 210 & 2.74 & 1.1751 \\
$\begin{array}{l}\text { CM helps me to achieve bank goals and objectives. } \\
\begin{array}{l}\text { My bank focuses on individual employees by analyzing the needs and } \\
\text { proposing solutions that bring business competency. }\end{array}\end{array}$ & 210 & 2.76 & 1.2766 \\
\hline
\end{tabular}


My skills in relationship building and maintaining a good relationship with peers, subordinates, and superiors are assessed by the bank.

For the statement "CM helps me to achieve bank goals and objectives" the mean value calculated was 2.76 which indicates that respondents are agreeing to the statement to some extent. Another statement "My bank focuses on individual employees by analyzing the needs and proposing solutions which bring business competency" has a mean value 2.7 which means that respondents are somewhat agreeing to the statement. Likewise, for the statement "My skills on relationship building and maintaining a good relationship with peers, subordinates, and superiors are assessed by the bank" the mean value computed was 2.88 which suggests that respondents are agreeing to the statement to some extent. The highest mean relates to "We are often motivated to find an unusual solution to the problem" presenting 2.91 that indicate respondents are agreeing to the statement to some extent. Lastly, for the statement "My job gives me a chance to challenge my limits" the computed mean value was 2.78 which means that respondents are somewhat agreeing to the statement.

Summing above the respondents present similar views in regard to showing the agreement to the given statements in regard to business competency needed to carry out their jobs efficiently. However except to the statement I am required to sit the whole day in the office, the average perception of the respondents was somewhat agree. In case of the statement I am required to sit the whole day in the office they show their perception in the second scale agree. The overall average perception of respondents regarding business competency was somewhat agree.

\section{Employee Performance Improvement}

Six questions were asked regarding employee performance improvement. The respondents were requested to indicate their views in the scale as strongly agree (1), agree (2), agree somewhat (3), less agree (4) or least agree (5).Table No. 2 shows the mean and standard deviation of employee performance improvement of bankers. A mean less than 3 indicates that business competency makes a good impact on employee performance improvements. Whereas mean higher than 3 indicates that they less agree and least agree with the business competency makes a good impact on employee performance improvements. Similarly, the mean equal to 3 indicates that the respondents are agreeing somewhat to the statement.

As shown in table 2, for the first statement "My bank inspires the best in me in the way of job performance" the mean value computed was lowest i.e. 2.63 which means that respondents are somewhat agreeing to the statement. In the case of a statement, "Competitive Mapping has provided me with skills and knowledge that has improved my performance" the computed mean value was 2.77 which means that respondents are agreeing to the statement to some extent. The highest mean relates to "Bank policy of pay and benefit recognize my potential and accomplishments" presenting 2.79 means that respondents are somewhat agreeing to the statement.

Table 2

Descriptive analysis of employee performance improvement

\begin{tabular}{lccc}
\hline Statements & $\mathrm{N}$ & Mean & Std. Deviation \\
\hline $\begin{array}{l}\text { My bank inspires the best in me in the way of job performance. } \\
\text { Competitive Mapping has provided me with skills and knowledge that } \\
\text { have improved my performance. }\end{array}$ & 210 & 2.63 & 1.2466 \\
\hline
\end{tabular}


Bank policy of pay and benefit recognizes my potential and accomplishments.

My bank encourages creativity, innovation, and continuous

improvement.

I find my job very exciting and look forward to new assignments.

I am required to work in a systematic and organized manner.

Employee Performance Improvement
$210 \quad 2.79 \quad 1.1466$

$210 \quad 2.77$

$\begin{array}{lll}210 & 2.73 & 1.2699\end{array}$

$210 \quad 2.75 \quad 1.2785$

$210 \quad 2.74 \quad 1.2318$

According to table 2, for the statement "My bank encourages creativity, innovation, and continuous improvement" the mean value computed was 2.77 which suggests that respondents are agreeing to the statement to some extent. Another statement "I find my job very exciting and look forward to new assignments" has a mean value 2.73 which means that respondents are somewhat agreeing to the statement. Lastly, for the statement "I am required to work in a systematic and organized manner" the computed mean value was 2.74 which means that respondents are somewhat agreeing to the statement.

In a nutshell, all most all respondents irrespective of differences in their organizational settings have the same level of perception about the statement regarding performance improvement.The average perception of the employees represent that they agree somewhat to the statements related with the performance improvement.

\section{Correlation Analysis}

Correlation Analysis between variables was studied to find relations among them. Pearson's Correlation analysis is used to determine the relationship between various independent and dependent variables associated with the research. It measures the linear correlation between any two variables.

Table 3 shows the correlation analysis of the dependent and independent variables of respondents working in banks. It shows the relationship between employee performance improvement and business competency.

Table 3

Correlation Analysis

Independent Variables $\quad$ Employee performance improvement

$\begin{array}{lll} & \text { Pearson Correlation } & .877^{* *} \\ \text { Business Competency } & \text { Sig. (2-tailed) } & 0.000 \\ & \text { N } & 210\end{array}$

Correlation is significant at the 0.05 level (2- tailed)

The correlation analysis results presented in the above table show that the Pearson Correlation Coefficient between business competency and employee performance improvement is $r=0.877$, which implies that the two variables are highly correlated. Further, this value indicates that there is a high correlation between business competency and employee performance improvement. The correlation is significant at a $5 \%$ level of significance as the $\mathrm{p}$-value is less than $\alpha<0.05$.

\section{Conclusion}

Today the business is epitomized by the contemporary issues like global operations, workforce diversity, transitions, paradigm shifts, the pressure of competition, wealth creation, shareholder 
value creation, customer focus, culture, and value-based product, and context-based approach. All these issues have raised a worldwide concern for competencies. To survive, grow and bring the timely changes the organization, the modern companies should plan and activate the competency development program continuously. The findings of this research also acknowledge the importance of employees' business competency and its relationship with employees' performance. Comparatively, companies with appropriately competent employees can achieve its success through employees' performance improvement.

\section{Implications}

This research has several implications for practice and research. For practitioners, we recommend that competency plays a vital role in the performance improvement of their companies. Therefore, they should organize competency development program periodically, so that employees be ready to accept each challenge posed by the changing external and internal environment. Profit seeking companies should invest in the competency development program for their employees. The future researchers are requested to study other facets of employees' competency with a larger representation of respondents with other sophisticated statistical measurement and tools in the cross and multi-functional organizations.

\section{References}

Abdullah , A. H., Musa , R., \& Ali, J. H. (2011). The Development of Human Resource Practitioner Competency Model Perceived by Malaysian Human Resource Practitioners and Consultants: A Structural Equation Modeling (SEM) Approach. International Journal of Business and Management, 240.

Aitchison, D. (2007). HR Transformation: Myth or Reality. HROA Europe and Sharedpertise Forums in Association with TPI.

Armstrong, M. (2005). A handbook of human management practice. London: Kogan Page Limited.

Athey, T. R., \& Orth, M. S. (1999). Emerging Competency Methods for the Future. Human Resource Management, 215-226.

Avkiran, N. (2000). Interpersonal skills and emotional maturity influence entrepreneurial style of bank managers. American Psychological Association , 654-675.

Baker, J., Mapes, J., New, C., \& Szwejczewsk. (1997). A hierarchical model of business competence. Integrated Manufacturing Systems, 265-72.

Barret, G. V., \& Depinet, R. L. (1991). A reconsideration of testing for competence rather than intelligence. American Psychologist, , 1012-1024.

Becker, B., \& Huselid, M. (1998). High Performance Work Systems and Firm Performance: A Synthesis of Research and Managerial Applications. Research in Personnel and Human Resources Management, 53-101.

Boselie, P., \& Paauwe, J. (2005). HRM and performance: what next? Ithaca, NY: Cornell University, School of Industrial and Labor Relations, Center for Advanced Human.

Boxall, P., \& Dowling, P. (1990). Human Resource management and the industrial relations. Tradition, labour and industry, 27-42.

Boyatzis, R. E. (1982). The Competent Manager: A Model for Effective Performance. New York, NY: John Wiley \& Sons.

Budhwar, P. S., \& Debrah, Y. A. (2001). Human resource management in developing countries. Routledge.

Caupin, Gills; International Project Management Association. (2006). ICB - IPMA Competence Baseline, version 3.0. International Project Management.

Chartered Institute of Personnel and Development . (2007). The Changing HR Function. London: CIPD

Chen, A. S.-y., Bian, M.-d., \& Hom, Y.-m. (2005). Taiwan HRD Practitioner Competencies: An application of the ASTD WLP Competency model. International Journal of Training and Development, 21- 32.

Delamare Le Deist, F., \& Winterton, J. (2005). What Is Competence? Human Resource Development 
International, 27-46.

Drejer, A. (2001). How we define and understand competencies. Technovation, 135-146.

Dulewitz, V. (1991). Assessment centers as a route to competence. Personnel Management, 56-59.

Egodigwe, L. (2006). Pipeline to success. Black Enterprise, 59.

Escrig-Tena, A., \& Bou-Llusar, J. (2005). A model for evaluating organizational competencies: an application in the context of a quality management initiative. Decision Sciences, 221-257.

Ferman, \& Ozcelik. (2006). Competency Approach to Human Resource Management Outcomes and Contributions in a Turkish Cultural Context. Human Resource Development Review 2006, 72-91.

Frederick W. Gluck, S. P. (1980). Strategic Management for Competitive Advantage. Harvard Business Review Home.

Heinsman, H., De Hoogh, A. H., Vanmuijen, J. J., \& Koopman, P. L. (2006). Competency Management: Balancing Between Commitment and Control. Management Revue, 292-306.

Heisler, J. (2003). Competency Today Required by Today HRM Professionals. Link \& Learne Newsletter.

Hong, J., \& Ståhle, P. (2005). The coevolution of knowledge and competence management. International Journal of Management Concepts and Philosophy, 129-45.

Hsu, Y.-R., \& Leat, M. (2000). A study of HRM and recruitment and selection policies and practices in Taiwan. The International Journal of Human Resource Managemen, 413-415.

Javidan, M. (1998). Core competence: What does it mean in practice? Long Range Planning, 60-71.

Junaidah, J. (2007). Exploring readiness for language learning autonomy among distance learners in Sabah. Malaysia Asian Journal of Distance Education, 16-26.

Kansal, J., Satyawali, P. K., Jain, N., \& Ganju, A. (2012). Competency mapping in knowledge based organizations. International Journal of Management, 279-290.

Katz, J., HE, A., T.M., W., \& P.M., W. (2000). Toward a new synthesis. Entrepreneurship Theory and Practice. Guest editor's comments special issue on human resource, 7-10.

Khatri , N. (1999). Emerging issues in Strategic HRM in Singapore. International Journal of Manpower, 16-29.

King, S. B., King, M., \& Rothwell, W. J. (2001). The complete guide to training delivery: A competencybased approach New York. American Management Association.

Lapiņa, I., Maurane, G., \& Starineca, O. (2013). Holistic Human Resource Management Model towards Sustainable and Sophisticated Business. Proceedings of the 17th World Multi-Conference on Systemics, Cybernetics and Informatics (pp. 31-36). Orlando: International Institute of Informatics and Systemics.

Leonard-Barton, D. (1995). Wellsprings of knowledge. Boston: Harvard Business School Press.

Loosemore, M., Nguyen, B., \& Denis, N. (2000). An investigation into the merits of encouraging conflict in the construction industry. Construction Management and Economics, 447-456.

McClelland, D. (1973). Testing for competence rather than for "intelligence". American psychologist. Mc Daniel. (1998). A competency Model for Human Resources. Massachusetts: HRD Press.

Nankervis, A. R., Compton, R. L., \& McCarthy, T. E. (1999). Strategic human resource management. Nelson Australia Ptv. Limited, 16-17.

Nybo, G. (2004). Personnel development for dissolving jobs: Towards a competency-based approach. International Journal of Human Resource Management, 549-564.

Qiao , J., \& Wang, W. (2009). Managerial competencies for middle managers: some empirical findings from China. Journal of European Industrial Training.

Quinn, R. W., \& Brockbank, W. (2006). The development of strategic human resource professionals at bae systems. Human Resource Management, 477- 494.

Ramachandran, R. (2006). Competency Mapping. National Conference on Emerging Trends in Business Research.

Ramlall, S. (2006). Identifying and Understanding HR Competencies and their Relationship to Organisational 
Practices. Applied HRM Research, 27-38.

Rothwell, W. J., Sanders, E. S., \& Soper, J. G. (1999). ASTD models for workplace learning and performance. Alexandria: American Society for Training and Development.

Sanchez, R., \& Heene, A. (1997). Strategic Learning and Knowledge Management. Chichester: John Wiley. Schoonover, S. (2003). Human resource competencies for the new century. Falmouth, MA:Schoonover Associates, Inc.

Selmer, J., \& Chiu, R. (2004). Required human resources competencies in the future: A framework for developing HR executives in Hong Kong. Journal of World Business, 324-336.

Selmer, C., \& Randy, K. (2004). Developing Human Competencies: The Hong Kong Case. BRC Papers on Human Resource Studies.

Selznick, P. (1957). Leadership in Administration: A Sociological Interpretation. Berkeley: University of California Press.

Sharma, D. (2013). Competency Mapping to Identify High Performers:in Context to IT Professionals. International Journal of Science and Research (IJSR).

Shermon, G. (2004). Competency based HRM: A strategic resource for competency mapping, assessment and development centres. New York: McGraw Hill Education.

Srivastava, V. S. (2014). Understanding Competencies and Competency Modeling - A Literature Survey. IOSR Journal of Business and Management (IOSR-JBM), 14-22.

Ulrich, D., \& Brockbank, W. (2005). HR value proposition. Boston: Harvard Business Press.

Vazirani, N. (2010). Competencies and Competency Model-A Brief overview of its Development and Application. SIES Journal of Management, 121-131.

White, R. W. (1959). Motivation reconsidered: The concept of competence. Psychological Review, 66, 297-323. 